\title{
Benign metastasizing leiomyoma: clonality, telomere length and clinicopathologic analysis
}

\author{
Kurt T Patton ${ }^{1}$, Liang Cheng ${ }^{2}$, Veronica Papavero ${ }^{1}$, Matthew G Blum ${ }^{3}$, Anjana V Yeldandi ${ }^{1}$, \\ Brian P Adley ${ }^{1}$, Chunyan Luan ${ }^{1}$, Leslie K Diaz ${ }^{1}$, Pei Hui ${ }^{4}$ and Ximing J Yang ${ }^{1}$ \\ ${ }^{1}$ Department of Pathology, Northwestern University, Feinberg School of Medicine, Chicago, IL, USA; \\ ${ }^{2}$ Department of Pathology and Laboratory Medicine, Indiana University Medical Center, Indianapolis, \\ IN, USA; ${ }^{3}$ Department of Cardiothoracic Surgery, Northwestern University, Feinberg School of Medicine, \\ Chicago, IL, USA and ${ }^{4}$ Department of Pathology, Yale University School of Medicine, New Haven, CT, USA
}

\begin{abstract}
Benign metastasizing leiomyoma is a rare condition affecting women with a history of uterine leiomyomata and is characterized by multiple histologically benign pulmonary smooth muscle tumors. Speculations on its pathogenesis include a benign uterine leiomyoma colonizing the lung, a metastatic low-grade uterine leiomyosarcoma, and primary pulmonary leiomyomatosis. To elucidate its pathogenesis, we analyzed the clinical, pathological and immunohistochemical features, clonality, and telomere length of multiple lung and uterine tumors in three patients with benign metastasizing leiomyoma. In all cases, pulmonary tumors had benign histology and immunohistochemical profiles (estrogen receptor positive, progesterone receptor positive, and very low proliferative index) identical to uterine leiomyoma. In eight tumors from three patients, clonality was assessed by analyzing the variable length of the polymorphic CAG repeat sequence within the human androgen receptor gene. In the two informative patients pulmonary and uterine tumors showed identical patterns of androgen receptor allelic inactivation, indicating that they were clonal. The telomere length measured by fluorescence in situ hybridization in pulmonary leiomyomas of all three patients were either long or very long and were identical to the uterine counterparts, indicating significant telomere shortening is not a crucial step for developing metastases. Our evidence supports the notion that benign metastasizing leiomyoma is clonally derived from benign-appearing uterine leiomyomas.
\end{abstract}

Modern Pathology (2006) 19, 130-140. doi:10.1038/modpathol.3800504

Keywords: clonality; telomere; pulmonary; leiomyoma; metastasis

Benign metastasizing leiomyoma is a lesion characterized by usually multiple, benign-appearing smooth muscle tumors of the lung ${ }^{1,2}$ in females with coexisting uterine leiomyoma. The nature of benign metastasizing leiomyoma has been debated since it was first reported in the English literature in $1939 .^{3}$ In contrast to the original hypothesis that this was a benign leiomyoma colonizing the lung, some investigators believed it was a low-grade leiomyosarcoma $^{4}$ while others argued that it may represent primary pulmonary leiomyomatosis coexisting with a uterine leiomyoma. As a result of its rarity, only very limited molecular analyses have been performed and reported for this condition.

Correspondence: Dr XJ Yang, MD, PhD, Department of Pathology, Feinberg 7-334, Northwestern Memorial Hospital, Northwestern University, Feinberg School of Medicine, 251 East Huron Street, Chicago, IL 60611, USA.

E-mail: xyang@northwestern.edu

Received 18 May 2005; revised 16 August 2005; accepted 26 August 2005
In recent years, the development of sophisticated molecular assays has enhanced our understanding of the development of neoplastic lesions. X-chromosome inactivation has become a powerful technique allowing investigators to study clonality of tumors and their metastases. Using this method, Tietze et $a l^{5}$ recently provided evidence for clonality in a single case of benign metastasizing leiomyoma. However, since there is a $50 \%$ chance that the same X-inactivation could occur incidentally between two tumors, more cases should be analyzed using this method. Telomere shortening, a possible crucial event leading to chromosomal instability and development of malignancy, has been reported in multiple types of human cancer $^{6-9}$ and can be demonstrated with telomerespecific fluorescence in situ hybridization (FISH) probes.

In this study, we compared the clinical, pathological, and immunohistochemical features of lung lesions and uterine lesions from three patients with benign metastasizing leiomyoma. In addition, we 
compared the telomere lengths and analyzed clonality of these tumors hoping to understand the nature of these tumors.

\section{Materials and methods}

\section{Clinical Information}

Patient 1 was an otherwise healthy 44-year-old who presented with abnormal uterine bleeding and underwent operative hysteroscopy for resection of submucosal uterine leiomyomas. After 2 months, a contrast-enhanced computed tomographic scan (CT scan) at the level of the hilum taken from this patient showed multiple, small, round, well-defined enhancing nodules in the right and left lung fields (Figure 1). Many additional small nodules were visible in the remaining thoracic CT scan images (not shown). A lung wedge biopsy specimen demonstrated four nodules, ranging from 1 to $7 \mathrm{~mm}$ in greatest dimension. Two pulmonary tumor nodules and one uterine tumor from this patient were analyzed. Patient 2 was 37-year-old who underwent abdominal myomectomy for leiomyomas $3 \frac{1}{2}$ years prior to presenting with multiple, small pulmonary nodules. A wedge biopsy specimen yielded a single $15 \mathrm{~mm}$ nodule. One pulmonary tumor nodule and one uterine tumor from this patient were analyzed. Patient 3 was 44-year-old who underwent abdominal myomectomy at the age of 39 years. After 5 years a chest CT showed multiple small bilateral pulmonary nodules. A wedge biopsy yielded four nodules, ranging from 2 to $6 \mathrm{~mm}$ in greatest dimension. Two pulmonary tumor nodules and one uterine tumor from this patient were further analyzed. The clinical information of these three patients is summarized in Table 1.

\section{Immunohistochemistry}

Immunohistochemical staining was performed on $4 \mu \mathrm{m}$ sections cut from formalin-fixed, paraffinembedded tissue deparaffinized in xylene and then rehydrated in a series of alcohols. For antigen retrieval, sections were microwave pressure cooked for $20 \mathrm{~min}$ in citrate buffer at $\mathrm{pH}$ 6.0. The immunohistochemistry was performed with a Ventana Benchmark or Ventana ES automated immunostainer (Ventana Medical Systems, Tucson, AZ, USA) using monoclonal antibodies specific for estrogen receptor (ER) (Ventana, clone 6F11, $1 \mu \mathrm{g} / \mathrm{ml}$ ), progesterone receptor (PR) (Ventana, clone 1A6, $1 \mu \mathrm{g} /$ ml), Ki-67 (Ventana, $8 \mu \mathrm{g} / \mathrm{ml}$ ), HMB45 (DakoCytomation, Carpinteria, CA, USA 1:50 dilution), and CD31 (DakoCytomation, clone JC/70A, 1:40). Slides were incubated for $30 \mathrm{~min}$ at room temperature with primary mouse monoclonal antibodies, then incubated with biotin-labeled rabbit anti-mouse secondary antibody, washed, and blocked with

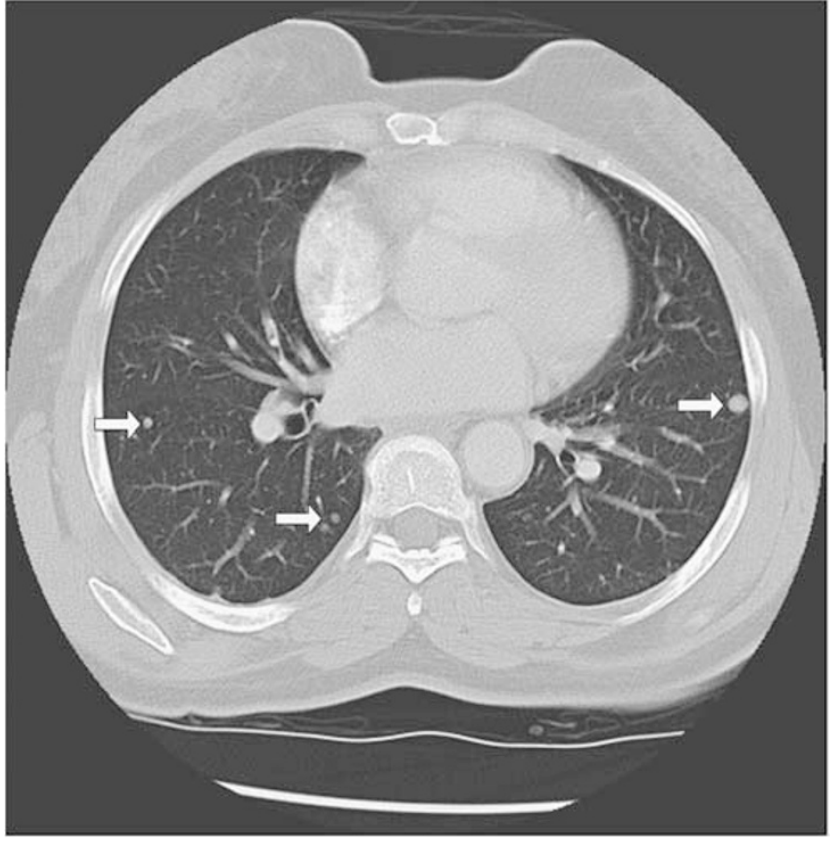

Figure 1 Thoracic imaging by computed tomography scan. An early phase contrast-enhanced CT scan from Patient 1 taken at the level of the pulmonary hilum shows multiple, small, round, well circumscribed enhancing lesions (arrows). Their distribution is typical of metastatic lesions.

Table 1 Summary of clinical, pathological, immunohistochemical, and other analyses in three patients with benign metastasizing leiomyoma

\begin{tabular}{|c|c|c|c|}
\hline & Patient 1 & Patient 2 & Patient 3 \\
\hline Age (years) & 44 & 37 & 44 \\
\hline Uterine tumor & Yes & Yes & Yes \\
\hline Interval (months) ${ }^{\mathrm{a}}$ & 2 & 41 & 60 \\
\hline Largest lung tumor (mm) & 9 & 15 & 6 \\
\hline Number of lung tumors & Multiple & Multiple & Multiple \\
\hline Number analyzed & 2 & 1 & 2 \\
\hline Cellularity & Low & Low & Moderate \\
\hline Necrosis & No & No & No \\
\hline Atypia & No & No & No \\
\hline Mitosis & $<1 / 50 \mathrm{hpf}^{\mathrm{b}}$ & $<1 / 50 \mathrm{hpf}$ & $<1 / 50 \mathrm{hpf}$ \\
\hline Ki-67 index & $<5 / 1000$ & $<5 / 1000$ & $<10 / 1000$ \\
\hline ER/PR expression & $+/+(100 \%)$ & $+/+(100 \%)$ & $+/+(100 \%)$ \\
\hline HMB-45 expression & Negative & Negative & Negative \\
\hline \multicolumn{4}{|l|}{ Monoclonality: } \\
\hline Lung tumors & Yes & Noninformative & Yes \\
\hline Uterine tumor & Yes & Noninformative & Yes \\
\hline \multicolumn{4}{|l|}{ Telomere length: } \\
\hline Lung tumors & Long & Very long & Long \\
\hline Uterine tumor & Long & Very long & Long \\
\hline
\end{tabular}

${ }^{\mathrm{a}}$ Interval between the detection of lung tumors and uterine tumor.

${ }^{\mathrm{b}}$ High-power field.

hydrogen peroxide. Avidin-horseradish peroxidase was added, and sections were developed with a Ventana 3,3'-diaminobenzidine solution. 


\section{Microdissection and Tumor Specimen Preparation}

Histologic sections were prepared from formalinfixed, paraffin-embedded tissue and stained with hematoxylin and eosin for histopathologic review. From these slides the tumors were identified. Laserassisted microdissection of lesional tissue was performed on unstained sections using a PixCell II Laser Capture Microdissection (LSM) system (Arcturus Engineering, Mountain View, CA, USA), as previously described. ${ }^{10,11}$ Approximately 400-1000 cells of each tumor were microdissected from the $5 \mu \mathrm{m}$ histologic sections. Normal tissue not involved by the tumor from each sample was microdissected as a comparison.

\section{Detection of X-Chromosome Inactivation}

To amplify the CAG repeat in the human androgen receptor gene $(A R)$, DNA samples were prepared from distinctly separate tumors from the same patient. The dissected cells were placed in $15 \mu \mathrm{l}$ of buffer (10 mM Tris-HCl, $1 \mathrm{mM}$ EDTA, 1\% Tween 20 , and $0.2 \mathrm{mg} / \mathrm{ml}$ of proteinase $\mathrm{K}(\mathrm{pH}$ 8.3) $)$ and incubated overnight at $37^{\circ} \mathrm{C}$. The solution was boiled for $10 \mathrm{~min}$ to inactivate the proteinase $\mathrm{K}$ and used directly for subsequent clonal analysis without further purification. Aliquots $(8 \mu \mathrm{l})$ of the DNA extract were digested overnight at $37^{\circ} \mathrm{C}$ with $1 \mathrm{U}$ of HhaI restriction endonuclease (New England Biolabs Inc., Beverly, MA, USA) in a total volume of $10 \mu$ l. Equivalent aliquots of the DNA extracts were also incubated in the digestion buffer without HhaI endonuclease as control reactions for each sample. After the incubation, $3 \mu \mathrm{l}$ of digested or nondigested DNA was amplified in a $25-\mu$ l polymerase chain reaction (PCR) volume containing $0.1 \mu \mathrm{l}$ ${ }^{32}[\mathrm{P}] \alpha$-labeled deoxyadenosine triphosphate (dATP) $(3000 \mathrm{Ci} / \mathrm{mmol}), 4 \mu \mathrm{M} A R$-sense primer $\left(5^{\prime}\right.$ TCCAGAATCTGTTCCAGAGCGTGC3 $\left.{ }^{\prime}\right), \quad 4 \mu \mathrm{M} \quad A R$ antisense primer (5'GCTGTGAAGGTTGCTGTTC CTCAT3'), $4 \%$ dimethyl sulfoxide, $2.5 \mathrm{mM} \mathrm{MgCl}_{2}$, $300 \mu \mathrm{M}$ deoxycytidine triphosphate, $300 \mu \mathrm{M}$ deoxythymidine triphosphate, $300 \mu \mathrm{M}$ deoxyguanosine triphosphate, $300 \mu \mathrm{M}$ dATP, and $0.13 \mathrm{U}$ Taq DNA polymerase (Perkin-Elmer Corp., Norwalk, CT, USA). Each PCR amplification had an initial denaturation step of $95^{\circ} \mathrm{C}$ for $8 \mathrm{~min}$, that was followed by 32 cycles at $95^{\circ} \mathrm{C}$ for $40 \mathrm{~s}$, at $63^{\circ} \mathrm{C}$ for $40 \mathrm{~s}$, and at $72^{\circ} \mathrm{C}$ for $60 \mathrm{~s}$. This was then followed by a single final extension step at $72^{\circ} \mathrm{C}$ for $10 \mathrm{~min}$. The PCR products were then diluted with $4 \mu \mathrm{l}$ of loading buffer containing 95\% formamide, $20 \mathrm{mM}$ EDTA, $0.05 \%$ bromphenol blue, and $0.05 \%$ xylene cyanole FF (Sigma Chemical Co., St Louis, MO, USA). The samples were heated to $95^{\circ} \mathrm{C}$ for $5 \mathrm{~min}$ and then placed on ice. Of the reaction mixture, $3 \mu \mathrm{l}$ was loaded onto $6.5 \%$ polyacrylamide-denaturing gels without formamide, and the PCR products were separated by electrophoresis at $1600 \mathrm{~V}$ for $4-7 \mathrm{~h}$. The bands were visualized after autoradiography with Kodak X-OMAT AR film (Eastman Kodak Company, Rochester, NY, USA) for 8-16 h.

\section{Analysis of X-Chromosome Inactivation}

The cases were considered to be informative if two $A R$ allelic bands were detected after PCR amplification in normal control samples that had not been treated with HhaI. Only informative cases (ie, those without a skewed pattern of X-chromosome inactivation after being treated with HhaI in normal control samples) were included in the analysis. In tumor samples nonrandom X-chromosome inactivation was defined as a complete or a nearly complete absence of an $A R$ allele after HhaI digestion indicating a predominance of one allele. Tumors were considered to be monoclonal if the same $A R$ allelic inactivation pattern was detected in different tumors from the same patient. Tumors were considered to be multiclonal if alternate predominance of $A R$ alleles after HhaI digestion (different allelic inactivation patterns) was detected in different tumors from the same patient. Tumors with different allelic inactivation patterns were considered to be of independent origin. ${ }^{12}$

\section{Analysis of Telomere Length by Flourescent In Situ Hybridization}

Telomere length was quantified by a method using Cy3-labeled FISH probes specific for the mammalian telomere repeat sequence as described previously. ${ }^{6}$ Briefly, $4 \mu \mathrm{m}$ sections cut from formalin-fixed, paraffin-embedded tissue were incubated with custom made FISH probes (Applied Biosystems, Framingham, MA, USA) having the sequence $\mathrm{NH}_{3}$ CCCTAACCCTAACCCTAA-COOH and were incubated at room temperature for $2 \mathrm{~h}$ following a denaturation step at $83^{\circ} \mathrm{C}$ for $4 \mathrm{~min}$. Using a fluorescent microscope (Canon, USA), FISH telomere signals from tumors cells were compared to those from adjacent normal tissues. Telomere length was measured in a semiquantitative method with the following previous established criteria: ${ }^{6}$ very short (signal almost undetectable), short (signal visible but less intense than in normal surrounding tissue), normal (signal the same as normal tissue), long (signal stronger than normal tissue), and very long (signal intensity the same as lymphocytes which consistently have very bright telomere signals).

\section{Results}

Microscopically, pulmonary tumors were well circumscribed in all three patients (Figure 2a, d, and g) and were composed of monomorphic spindle cells with elongated oval-shaped nuclei containing inconspicuous nucleoli arranged in broad, intersect- 
ing fascicles lying within a collagenous background. In all patients inclusions of respiratory epithelium were surrounded by a cuff of scattered chronic inflammatory cells (Figure 2b, e, and h). Focal epithelioid change and stromal hyalinization were occasionally noted, but cytological atypia was not identified. The uterine smooth muscle tumors (Figure 2c, f, and i) demonstrated histology identical to that of the pulmonary tumors. Necrosis was not observed in any of the tumors. Mitotic activity was less than one per 50 high-powered fields in all tumors analyzed. In the uterine leiomyoma from Patient 1, a cluster of tumor cells was noticed bulging into a vein (Figure 2j), which was confirmed by a CD31 immunostain highlighting the endothelial cells (Figure 2k). Histological features are summarized in Table 1.

ER and PR expression was evaluated in all tumors. Two pulmonary tumors (Figures $3 a-c$ and $d-f$ ) and a uterine tumor (Figure 3g-i) from Patient 1 showed a strong, diffuse, nuclear pattern of ER (Figures 3a, d, and g) and PR (Figures $3 \mathrm{~b}$, e, and h) expression in
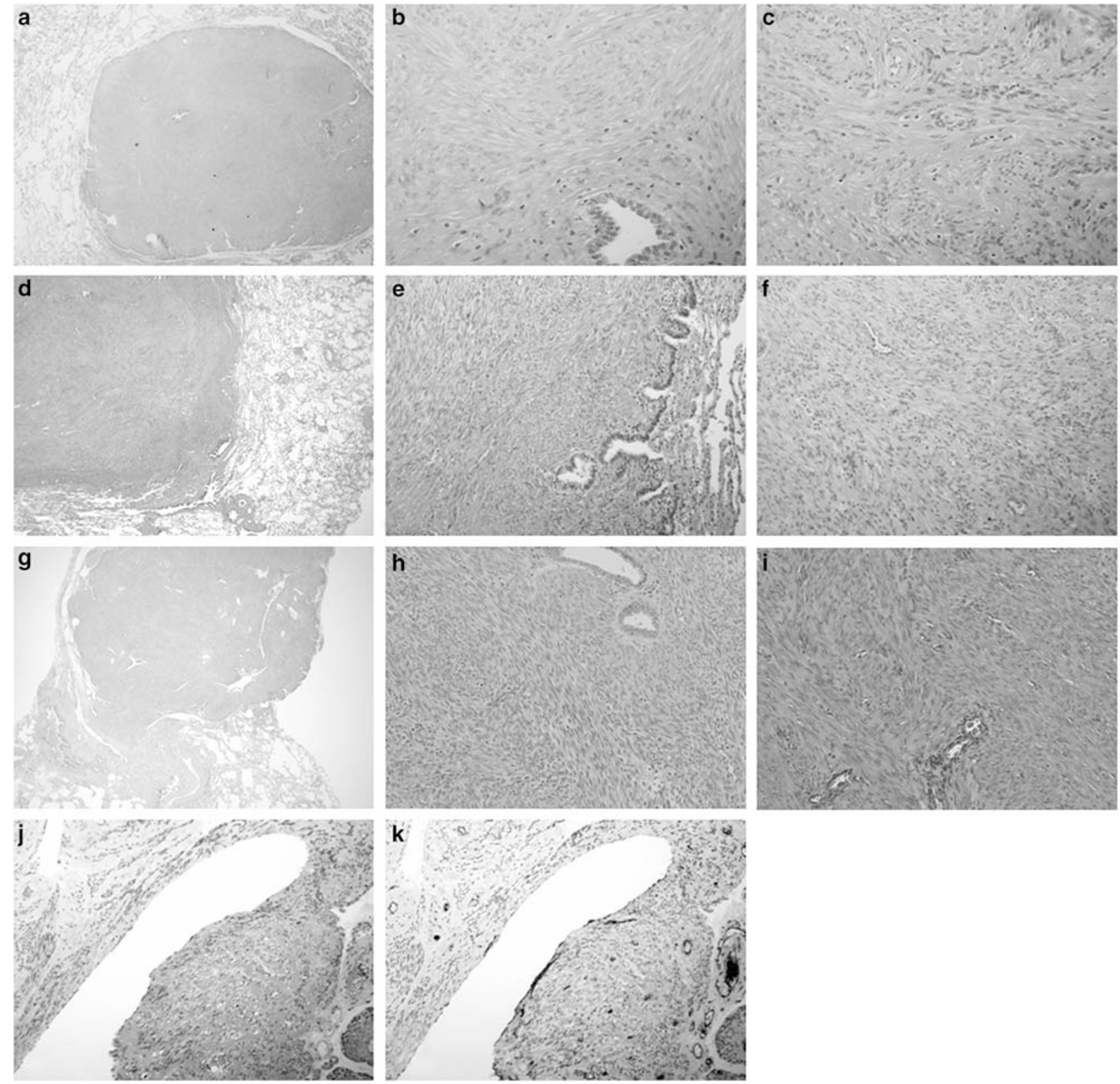

Figure 2 Histology of pulmonary and uterine tumors. Pulmonary nodules from Patients 1, 2 and 3 are well circumscribed (a, d, and g) and are composed of smooth muscle cells arranged in broad, intersecting fascicles with entrapped bronchial epithelium (b, e, and $\mathbf{h}$, high magnification). Uterine smooth muscle tumors from Patients 1, 2 and 3 (c, f, and i) show similar histology to pulmonary tumors. A cluster of tumor cells in the uterine leiomyoma from Patient 1 is seen bulging into a vein (j), and is confirmed with a CD31 immunostain (k). 
$100 \%$ of the tumor cells by immunohistochemical staining. Pulmonary tumors (Figures $3 \mathrm{j}-\mathrm{l}$ and $\mathrm{m}-\mathrm{O}$ ) and a uterine tumor (not shown) from Patients 2 and 3 showed similar patterns of positive ER (Figures $3 \mathrm{j}$ and $\mathrm{m}$, respectively) and $\mathrm{PR}$ (Figures $3 \mathrm{k}$ and $\mathrm{n}$, respectively) receptor expression, which supports the female genital origin of these tumors in all patients. Immunohistochemical staining for Ki-67, a proliferation marker, was performed. In tumors from Patient 1 , only rare cells $(<5 / 1,000)$ showed positive Ki-67 staining (Figures 3c, f, and i), in keeping with other reports of low Ki-67 proliferative index in benign metastasizing leiomyoma. ${ }^{13,14}$ Uterine (not shown) and pulmonary tumors from Patients 2 (Figure 31) and 3 (Figure 3o) showed a similar pattern of Ki-67 immunohistochemical staining $(<5 / 1,000$ and $<10 / 1,000$, respectively) which is consistent with a benign tumor. HMB-45 was negative in all tumors from all patients (photomicrographs not shown), excluding the possibility of a PEComa, especially clear cell 'sugar' tumor and lymphangiomyomatosis. Results of immunohistochemistry are summarized in Table 1.

$\mathrm{X}$-chromosome inactivation assays were performed on tissue microdissected from uterine and pulmonary tumors from three patients. A portion of pure tumor cells (Figure 4a, before dissection) was microdissected using an Arcturus PixCell II LCM system. The remaining section (Figure 4b, after dissection) and tumor cells collected for molecular analysis (Figure 4c) were examined. Analysis of two pulmonary tumors (T1 and T2) and one uterine tumor (T3) from Patient 1 revealed a pattern of nonrandom X-chromosome inactivation (Figure 5a) supporting a monoclonal origin. For Patient 2, analysis performed on the pulmonary and uterine tumors (T1 and T2, respectively) was noninformative; therefore, clonality of the pulmonary and uterine tumors in this patient could not be determined (Figure 5b). Analysis of two pulmonary tumors (T1 and T2) and one uterine tumor (T3) from Patient 3 revealed a pattern of nonrandom $\mathrm{X}$-chromosome inactivation (Figure 5c). Molecular analysis is summarized in Table 1.

The FISH telomere assay was carried out using a previously established semiquantitative $\operatorname{method}^{6}$ to measure and compare telomere length of the smooth muscle tumors for each patient. The pulmonary (Figure 6a) and uterine (Figure 6b) tumors from Patient 1 each demonstrated signal intensities stronger than surrounding normal tissue but not that of resident lymphocytes, consistent with long telomeres. The pulmonary (Figure 6c) and uterine (Figure 6d) tumors from Patient 2 showed signal intensities similar to resident lymphocytes, consistent with the tumors having very long telomeres. The pulmonary (Figure 6e) and uterine (Figure 6f) tumors from Patient 3 demonstrated signal intensities stronger than surrounding normal tissue but not that of resident lymphocytes, consistent with long telomeres. FISH analysis is summarized in Table 1.

\section{Discussion}

Metastasis, often leading to significant clinical complications and responsible for the majority of cancer-related deaths, is considered to unequivocally mark a tumor as malignant. However, it is known that seemingly benign processes like chorionic villi and endometrium can migrate to and colonize distant organs, and nevus cells can also migrate to regional lymph nodes. Ovarian epithelial borderline tumors often develop peritoneal implants that were originally recognized as a feature of malignancy. It is now known that borderline tumor implants, biologically different from carcinoma, may be treated effectively and carry a reasonably good prognosis.

Despite the common belief that benign tumors typically lack metastatic potential, Dr Steiner at the University of Chicago in $1939^{3}$ was the first to publish a report that described such a contradictory entity, namely benign 'metastasizing fibroleiomyoma.' Therein he reported a 36-year-old female with uterine leiomyomas who presented with cor pulmonale secondary to numerous pulmonary metastases which at autopsy were grossly and histologically benign and were identical to the uterine tumors. He believed that the lung lesions resulted from pulmonary spread of a histologically benign uterine tumors.

With only a few dozen cases reported in the English literature, ${ }^{1,15}$ benign metastasizing leiomyoma is a rare tumor primarily affecting the lungs of late reproductive-age women with a history of uterine leiomyomas. Recent case reports are summarized in Table 2. Over the last 66 years since Dr Steiner reported the first case, there has been much debate on the true nature of this lesion, a tumor with benign histological features but having biologic behavior suggesting malignancy. In attempts to explain its dichotomous nature, several hypotheses have been proposed: first, it could be a benign uterine tumor that spreads via a hematogenous route to the lungs or other organs, as a majority of patients have undergone myomectomy or hysterectomy suggesting surgically induced hematogenous spread; second, it could

Figure 3 Immunohistochemistry for estrogen receptor, progesterone receptor and Ki-67. Two pulmonary tumors (a-c and d-f, respectively) from Patient 1 show strong, diffuse, nuclear staining for estrogen (a, d) and progesterone (b, e) receptor. A uterine tumor (g-i) from Patient 1 shows strong, diffuse, nuclear staining for estrogen (g) and progesterone (h) receptor. Only rare cells $(<5 / 1,000)$ demonstrate expression of the proliferation marker, Ki-67, in pulmonary tumors (c, f) and the uterine tumor (i) from Patient 1. Pulmonary tumors from Patient $2(\mathbf{j}-\mathbf{l})$ and Patient $3(\mathbf{m}-\mathbf{o})$ show strong, diffuse, nuclear staining for estrogen $(\mathbf{j}, \mathbf{m})$ and progesterone $(\mathbf{k}, \mathbf{n})$ receptor. Only rare cells from Patients 2 and $3(<5 / 1,000$ and $<10 / 1000$, respectively) show expression of Ki-67 (l, o). 

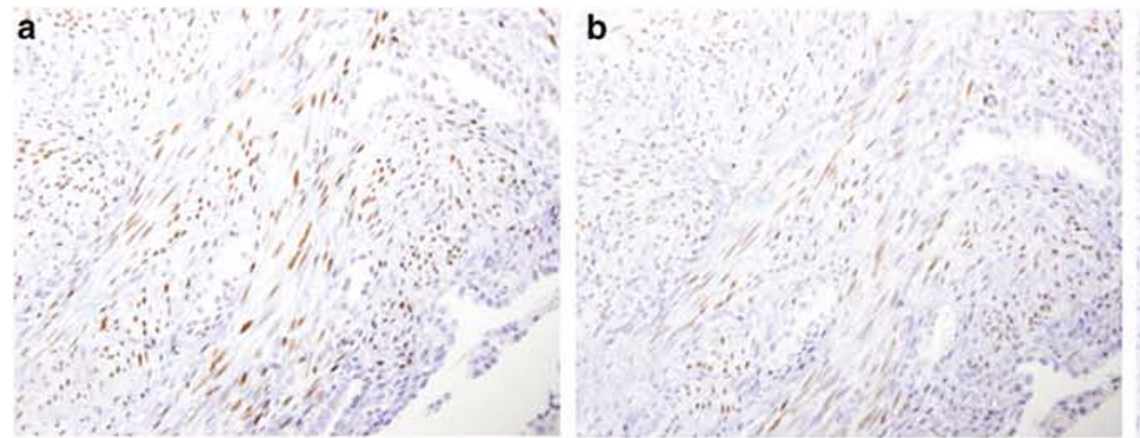

d

e

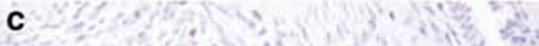
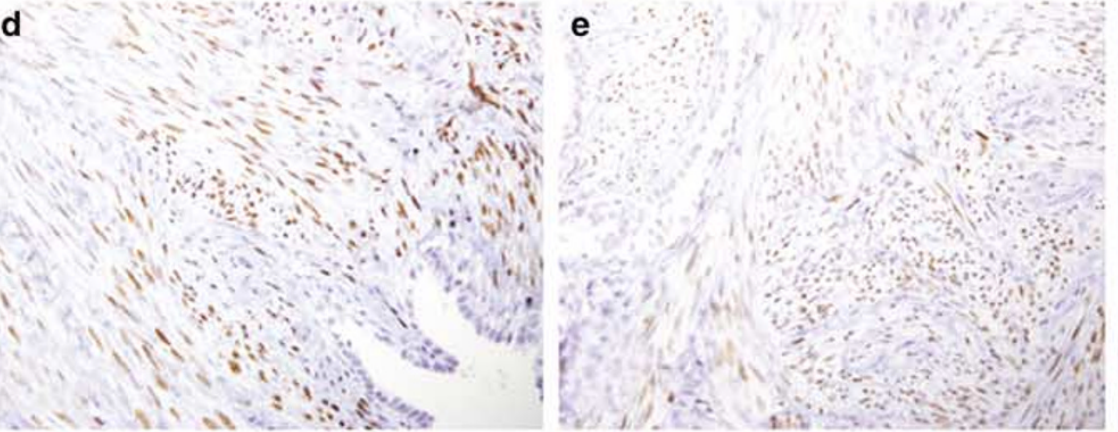

\section{f}
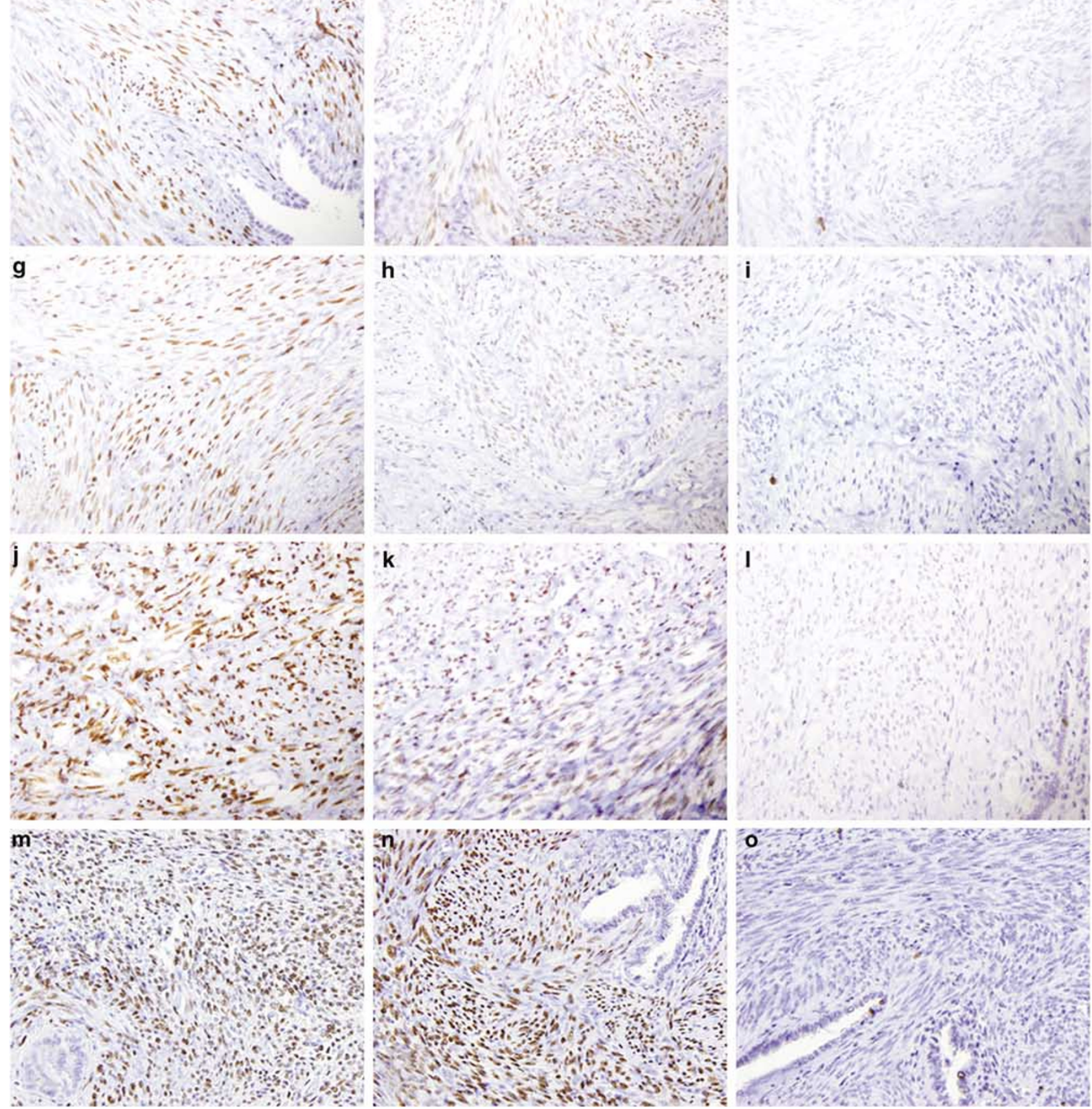

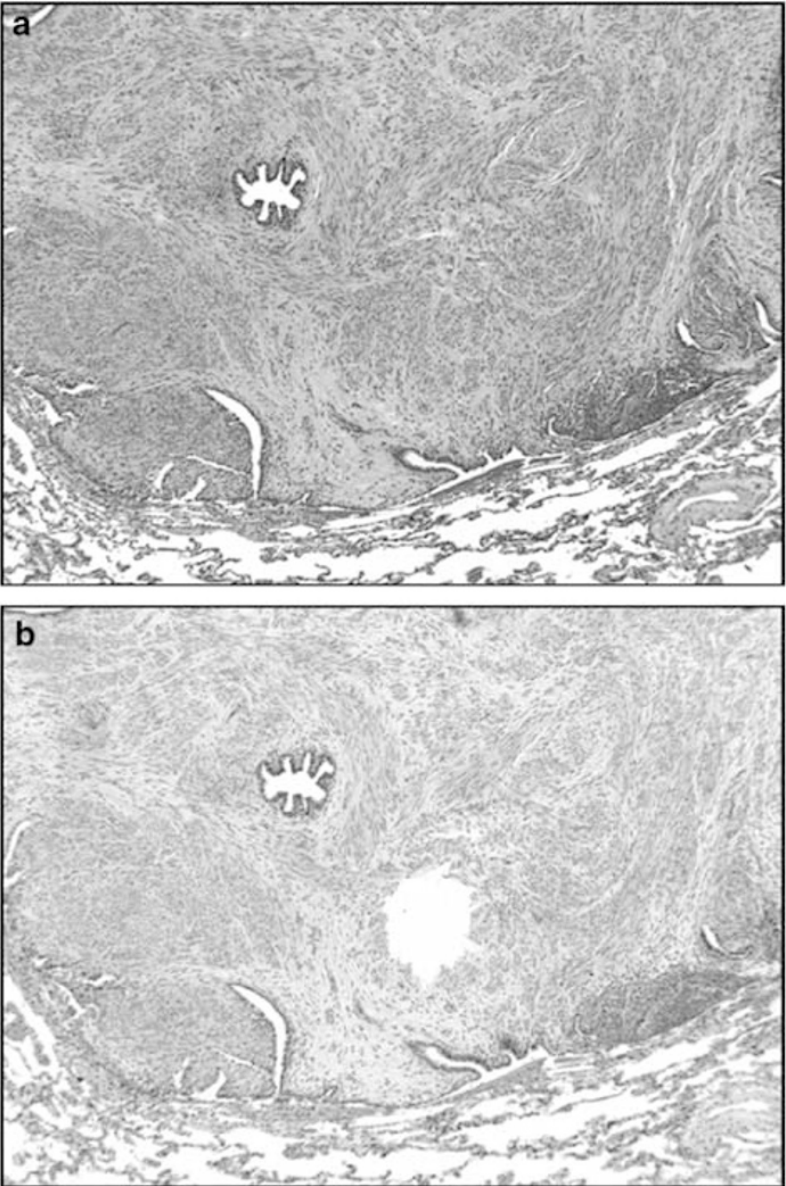

c

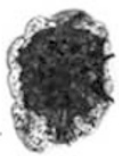

Figure 4 Laser-assisted microdissection of a lung tumor for Xchromosome inactivation analysis. (a) A pulmonary tumor from Patient 1 identified on standard H\&E section before dissection. (b) A portion of tumor tissue removed from an unstained section after dissection. (c) The portion of tumor selected for subsequent DNA isolation and analysis. a
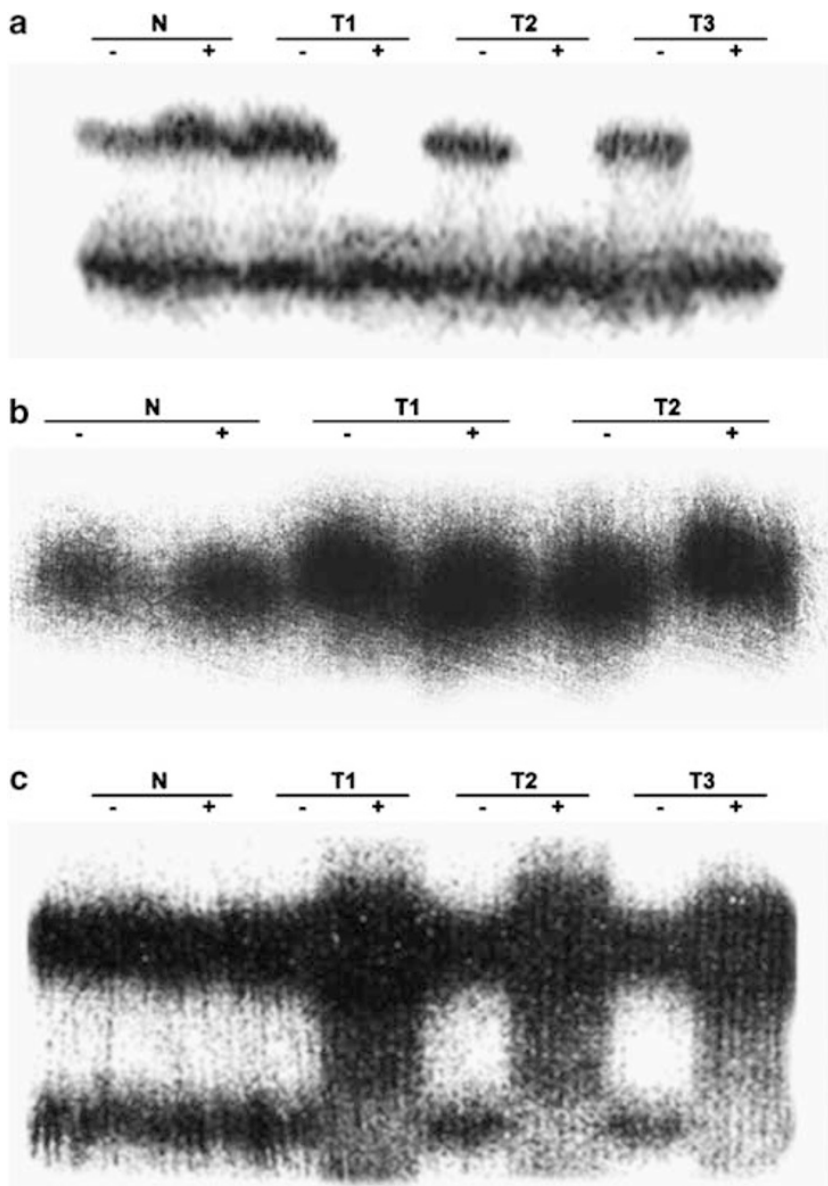

Figure 5 X-chromosome analysis for tumor clonality. (a) Analysis of pulmonary tumors (T1 and T2) and uterine tumor (T3) from Patient 1 demonstrates an identical pattern of nonrandom Xchromosome inactivation with complete or a nearly complete absence of an AR allele after $\mathrm{HhaI}$ digestion (+) indicating that the three tumors are derived from the same clone. (b) Pulmonary and uterine tumors (T1 and T2) from Patient 2 show a noninformative pattern of X-chromosome inactivation. (c) Analysis of pulmonary tumors (T1 and T2) and uterine tumor (T3) from Patient 3 demonstrates a pattern similar to that seen in Patient 1 indicating that the three tumors are derived from the same clone, $N=$ normal lung.

be a low-grade leiomyosarcoma metastasizing to the lung; ${ }^{2,4}$ and third, it could represent primary pulmonary leiomyomatosis unrelated to but coexisting with uterine leiomyomata. ${ }^{15}$

Benign metastasizing leiomyoma is morphologically benign. Based on the H\&E-stained sections, all eight tumors from three patients showed no evidence of high cellularity, cytological atypia, necrosis, or increased mitoses (Figure 2). Furthermore,

Figure 6 Fluorescence in situ hybridization assay for estimating relative telomere length. (a) Pulmonary tumor from Patient 1 with signals stronger than surrounding normal tissue (inset: respiratory epithelium). (b) Uterine tumor from Patient 1 with signals stronger than surrounding normal tissue (inset: myometrium). (c) Pulmonary tumor from Patient 2 with signals similar to resident lymphocytes (inset: respiratory epithelium). (d) Uterine tumor from Patient 2 with signals similar to resident lymphocytes and much stronger than surrounding normal tissue (inset: myometrium). (e) Pulmonary tumor from Patient 3 with signals stronger than surrounding normal tissue (inset: respiratory epithelium). (f) Uterine tumor from Patient 3 with signals stronger than surrounding normal tissue (inset: myometrium). 

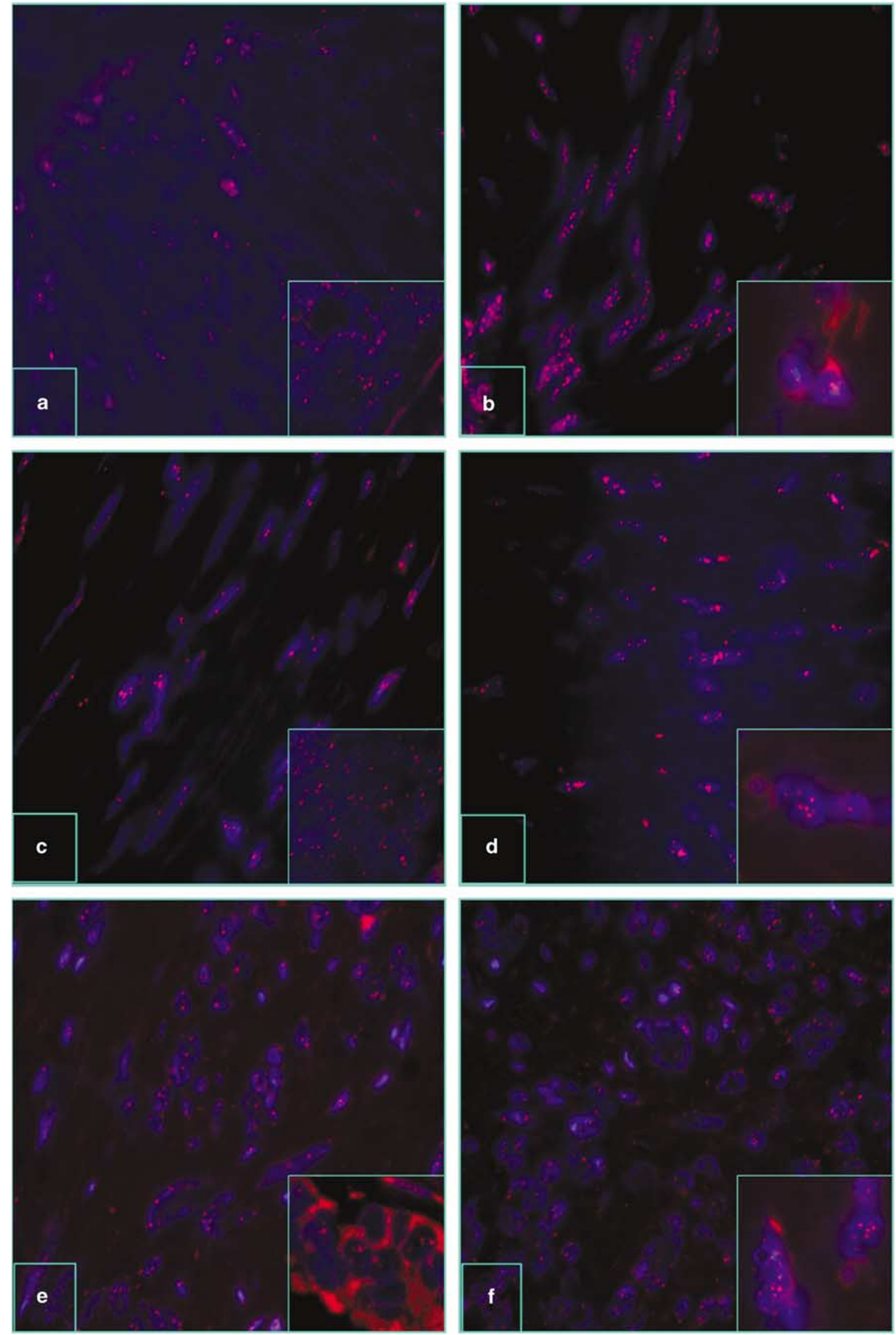
Table 2 Summary of recent reports of benign metastasizing leiomyoma

\begin{tabular}{|c|c|c|c|c|c|c|}
\hline Report & Cases & Age (years) & Interval (years) & Survival (months) & Status & Location \\
\hline Esteban et $a l^{16}$ & 1 & 72 & 4 & 24 & N/A & Lung \\
\hline Abramson et $a l^{17}$ & 7 & 47 (mean) & 8 (mean) & N/A & N/A & Lung \\
\hline Kayser et $a l^{14}$ & 10 & 35 (mean) & 15 (mean) & 43 (mean) & $\begin{array}{l}\text { AWD } \\
(9 / 10)\end{array}$ & Lung \\
\hline Pawlik et $a l^{18}$ & 1 & 41 & 4 & 12 & AWD & Lung \\
\hline Goyle et $a 1^{15}$ & 1 & 18 & 5 & 156 & AWD & Lung \\
\hline Joseph et $a l^{2}$ & 1 & N/A & N/A & 5 & DOD & Spine \\
\hline Lawson et $a l^{19}$ & 1 & 52 & 8 & N/A & N/A & Lung \\
\hline Rivera et $a 1^{20}$ & 2 & 42 (mean) & 12 (mean) & 6 (mean) & N/A & Lung \& spine \\
\hline Funakoshi et $a l^{21}$ & 1 & 77 & 12 & N/A & N/A & Lung \\
\hline \multirow[t]{2}{*}{ Patton et al (2005) } & 3 & 42 (mean) & 11 (mean) & 7 (mean) & AWD & Lung \\
\hline & 28 (total) & 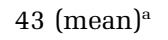 & $11{(\text { mean })^{\mathrm{a}}}$ & 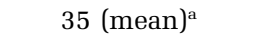 & & \\
\hline
\end{tabular}

$\mathrm{N} / \mathrm{A}=$ not available $; \mathrm{AWD}=$ alive with disease $; \mathrm{DOD}=$ dead of disease

${ }^{\mathrm{a}}$ Calculated from available data.

Ki-67 index was very low (Figures 3c, f, i, l, and o) supporting the low proliferative state of these tumors. Based on our studies and previous reports, there are several reasons why benign metastasizing leiomyoma is unlikely a primary lung leiomyoma in the vast majority of cases. First, like the subjects in our study, all the patients so far described are females of late reproductive age (Table 2) with a history of, or coexisting, uterine leiomyomas. Next, morphological, immunohistochemical, and molecular analyses in this and another report ${ }^{5}$ demonstrate that the lung tumors and uterine tumors are identical in their morphology, immunohistochemical features, and clonal origin. Although multifocality is a remote possibility, ${ }^{4}$ with the exception of a couple of case reports (Table 2), ${ }^{2,4}$ coexisting leiomyomas in gastrointestinal tract, skin or other organs have not been reported in these patients. Two recent reports by Joseph et al and Rivera et al described such tumors metastasizing to the spine. After close scrutiny of available histology provided in the previous reports, we feel that these spinal tumors, showing significant cytological atypia, are more consistent with leiomyosarcomas than with benign metastasizing leiomyomas. If benign metastasizing leiomyoma is a multifocal disease, we would expect leiomyomas or leiomyomatosis in other organs involving males as well as females. Next, our three cases and the majority of previous reports are strongly positive for ER and PR (8/10 reported by Kayser et $a l^{14}$ ), supporting the notion they are derived from the female genital tract. Lastly, in one of the cases (Patient 1), we observed subendothelial vascular involvement of the uterine leiomyoma (Figure 2j and k), possibly representing early vascular invasion with tumor embolus formation, and possibly demonstrating one mechanism of hematogenous spread of this tumor. However, secondary metastasis after initial lung metastasis, which should be numerous in a malignant tumor, has not been reported for benign metastasizing leiomyoma.
We used an X-chromosome inactivation assay to determine clonality in two of our three cases of benign metastasizing leiomyoma. Patient 1 demonstrated an identical X-chromosome inactivation pattern, indicating a monoclonal origin from uterine leiomyomas (Figure 5a). Analysis of Patient 2 was noninformative (Figure 5b), which does not exclude the possibility of the same origin, but does not support it either. Patient 3 also demonstrated an identical X-chromosome inactivation pattern (Figure 5c). From our findings and those of others, ${ }^{5}$ we draw the following conclusions: benign metastasizing leiomyoma is a neoplastic process; lung leiomyomas are clonally related to uterine leiomyomas; and benign metastasizing leiomyoma is different from primary pulmonary leiomyomatosis.

We determined the relative telomere lengths of five pulmonary metastases and three uterine tumors in three patients with benign metastasizing leiomyoma (Figure 6). In all three patients, the telomere length of pulmonary tumors was similar to that in the uterine ones, suggesting that telomere shortening is not a critical step in developing pulmonary metastasis, and that benign metastasizing leiomyoma clones are able to maintain telomere lengths similar to their primary uterine counterparts. However, the meaning of telomere length is a complicated subject. While it has been shown that telomere length correlates inversely, and telomerase activity directly, with malignancy in epithelial tumors, ${ }^{6-9}$ only a couple of studies address this question in soft tissue tumors. ${ }^{22,23}$ Bonatz et al measured telomere length in 107 uterine leiomyomas using a Southern blot method and found that telomeres were significantly shorter in tumoral tissue compared to adjacent uterine smooth muscle. In another study, Rogalla et $a 2^{24}$ showed that telomere lengths in uterine leiomyomas decreased on average 83 base pairs with each successive cell division. However, Terasaki et al assayed 83 sarcomas for telomerase activity and telomere length, and found no correlation between telomere length, telomerase activity, 
histologic grade, or patient's stage. To date an extensive survey of telomere length and telomerase activity in benign and malignant spindle cell tumors is lacking, and the significance of long and very long telomeres in our cases of benign metastasing leiomyoma is uncertain.

We believe that the name 'benign metastasizing leiomyoma' is currently appropriate for such a lesion considering pathological, legal, and social factors. First, we cannot make the diagnosis of sarcoma for this lesion based on any aforementioned histologic, immunohistochemical, cytogenetic, or molecular evidence. Second, although involvement of the lung by multiple small tumors may lead to pulmonary failure or cardiac failure ${ }^{3}$ most of the patients in the largest case series reported by Kayser et $a l^{14}$ with benign metastasizing leiomyoma had median survival of 43 months after lung biopsy and did not die of this disease (Table 2), even without receiving hormonal therapy. Finally, because of their uterine origin and the presence of high levels of ERs and PRs, medical treatment with drugs such as tamoxifen or raloxifene, both selective ER modulators, may be effective in cases where surgical resection is incomplete or not clinically indicated. ${ }^{18,20,25}$

In summary, our study supports the notion that 'benign metastasizing leiomyoma' is a result of monoclonal, hematogenous spread of a benignappearing uterine leiomyoma. This tumor possesses many morphologic, immunohistochemical, and molecular features characteristic of a benign neoplasm despite its potential for metastastic spread, which if neglected, may lead to shortened survival. Therefore, we believe benign metastasizing leiomyoma should be regarded as a borderline tumor or a tumor with low malignant potential. Since many cases of benign metastasizing leiomyoma are ER and PR positive, it may be treated with antihormonal therapy and/or surgical resection. Future molecular studies may lead to the discovery of markers identifying uterine smooth muscle tumors with the potential to develop benign metastasizing leiomyomas.

\section{Acknowledgement}

This paper contains findings from two abstracts presented at the United States and Canadian Academy of Pathology 2005 Annual Meeting, February 26-March 4, 2005, held in San Antonio, TX, USA.

\section{References}

1 Alessi G, Lemmerling M, Vereecken L, et al. Benign metastasizing leiomyoma to skull base and spine: a report of two cases. Clin Neurol Neurosurg 2003;105: 170-174.
2 Joseph V, Chacko G, Raghuram L, et al. Benign metastasizing leiomyoma causing spinal cord compression. Surg Neurol 2003;60:575-577.

3 Steiner P. Metastasizing fibroleiomyoma of the uterus: a report of a case and review of the literature. Am J Pathol 1939;15:89-109.

4 Cho KR, Woodruff JD, Epstein JI. Leiomyoma of the uterus with multiple extrauterine smooth muscle tumors: a case report suggesting multifocal origin. Hum Pathol 1989;20:80-83.

5 Tietze L, Gunther K, Horbe A, et al. Benign metastasizing leiomyoma: a cytogenetically balanced but clonal disease. Hum Pathol 2000;31:126-128.

6 Meeker AK, Hicks JL, Iacobuzio-Donahyue CA, et al. Telomere length abnormalities occur early in the initiation of epithelial carcinogenesis. Clin Cancer Res 2004;10:3317-3326.

7 Gertler R, Rosenberg R, Stricker D, et al. Telomere length and human telomerase reverse transcriptase expression as markers for progression and prognosis of colorectal carcinoma. J Clin Oncol 2004;22: 1807-1814.

8 Plentz RR, Wiemann SU, Flemming P, et al. Telomere shortening of epithelial cells characterises the adenoma-carcinoma transition of human colorectal cancer. Gut 2003;52:1304-1307.

9 Plentz RR, Caselitz M, Bleck JS, et al. Hepatocellular telomere shortening correlates with chromosomal instability and the development of human hepatoma. Hepatology 2004;40:80-86.

10 Brandli DW, Ulbright TM, Foster RS, et al. Stroma adjacent to metastatic mature teratoma after chemotherapy for testicular germ cell tumors is derived from the same progenitor cells as the teratoma. Cancer Res 2003;63:6063-6068.

11 Kernek KM, Ulbright TM, Zhang S, et al. Identical allelic losses in mature teratoma and other histologic components of malignant mixed germ cell tumors of the testis. Am J Pathol 2003;163:24772484.

$12 \mathrm{Gu}$ J, Roth LM, Younger C, et al. Molecular evidence for the independent origin of extra-ovarian papillary serous tumors of low malignant potential. J Natl Cancer Inst 2001;93:1147-1152.

13 Fukunaga M. Benign 'metastasizing' lipoleiomyoma of the uterus. Int J Gynecol Pathol 2003;22:202-204.

14 Kayser K, Zink S, Schneider T, et al. Benign metastasizing leiomyoma of the uterus: documentation of clinical, immunohistochemical and lectin-histochemical data of ten cases. Virchows Arch 2000;437: 284-292.

15 Goyle KK, Moore Jr DF, Garrett C, et al. Benign metastasizing leiomyomatosis: case report and review. Am J Clin Oncol 2003;26:473-476.

16 Esteban JM, Allen WM, Schaerf RH. Benign metastasizing leiomyoma of the uterus: histologic and immunohistochemical characterization of primary and metastatic lesions. Arch Pathol Lab Med 1999;123:960-962.

17 Abramson S, Gilkeson RC, Goldstein JD, et al. Benign metastasizing leiomyoma: clinical, imaging, and pathologic correlation. Am J Roentgenol 2001;176: 1409-1413.

18 Pawlik C, Wildberger JE, Tietze L, et al. Benign metastasizing leiomyoma of the lung-a rare differential diagnosis of pulmonary space-occupying lesions. Dtsch Med Wochenschr 2001;126:551-555. 
19 Lawson LM, Tiwari P, Filipenko JD. An unusual cause of an incidental lung mass. Can Respir J 2003;10:276-277.

20 Rivera JA, Christopoulos S, Small D, et al. Hormonal manipulation of benign metastasizing leiomyomas: report of two cases and review of the literature. J Clin Endocrinol Metab 2004;89:3183-3188.

21 Funakoshi Y, Sawabata N, Takeda S, et al. Pulmonary benign metastasizing leiomyoma from the uterus in a postmenopausal woman: report of a case. Surg Today 2004;34:55-57.

22 Terasaki T, Kyo S, Takakura M, et al. Analysis of telomerase activity and telomere length in bone and soft tissue tumors. Oncol Rep 2004;11:1307-1311.
23 Bonatz G, Frahm SO, Andreas S, et al. Telomere shortening in uterine leiomyomas. Am J Obstet Gynecol 1998;179:591-596.

24 Rogalla P, Rohen C, Hennig Y, et al. Telomere repeat fragment sizes do not limit the growth potential of uterine leiomyomas. Biochem Biophys Res Commun 1995;211:175-182.

25 Jautzke G, Muller-Ruchholtz E, Thalmann U. Immunohistological detection of estrogen and progesterone receptors in multiple and well differentiated leiomyomatous lung tumors in women with uterine leiomyomas (so-called benign metastasizing leiomyomas). A report on 5 cases. Pathol Res Pract 1996;192:215-223. 